Al-Huquq: Journal of Indonesian Islamic Economic Law, 3 (1), 2021: 14-33

ISSN: 2715-0003; E-ISSN 2714-5514

DOI: http://doi.org/10.19105/alhuquq.v3i1.4570

\title{
Nilai Wasathiyah dan Harakah dalam Hukum Ekonomi Syariah: Sebuah Pendekatan Filosofis Sikap dan Persepsi Bankir terhadap Bunga Bank
}

\author{
Doli Witro \\ (UIN Sunan Gunung Djati Bandung, Jl. A. H. Nasution No. 105, Cipadung, \\ Kecamatan Cibiru, Kota Bandung, Jawa Barat, 40614)
}

\begin{abstract}
Abstrak:
Dalam proses pinjam meminjam, seiring perkembangan zaman manusia dikenalkan dengan sebuah sistem yang bernama perbankan. Kini perbankan terkesan dan dianggap sebagai wadah yang menjalankan praktek riba. Dalam hal ini, hukum Islam sebagai hukum yang mempunyai karakteristik atau watak yang berbeda dengan hukum lainnya diharapkan dapat memberikan solusi atas permasalahan tersebut. Adapun karakteristik yang dimiliki hukum Islam yaitu takamul (sempurna), wasathiyah (seimbang) dan harakah (bergerak). Artikel ini menggunakan pendekatan kualitatif yang bersifat pustaka. Selain itu, artikel ini juga menggunakan pendekatan filosofis. Bahan-bahan yang digunakan dalam penelitian ini berasal dari buku-buku dan jurnal-jurnal. Data dalam artikel ini disajiakan dengan naratif-deskriptif. Teknik analisis yang digunkan adalah reduksi data, penyajian data, dan penarikan kesimpulan. Hasil analisis menunjukkan dalam filsafat hukum ekonomi syariah, nilai wasathiyah diartikan sebagai keseimbangan (pertengahan) dan harakah diartikan sebagai gerakan. Dalam menjawab permasalahan dalam ekonomi kontemporer diperlukan melihat dari sisi wasathiyah (keseimbangan) antara kedua belah pihak yang melakukan proses transaksi. Dengan menggunakan pendekatan filosofis yang berpedoman nilai wasathiyah dan harakah, terdapat tiga persepsi dan pandangan para bankir terhadap bunga bank yaitu bankir pragmatis, bankir realis-mondernis, dan bankir fundamentalis. (In lending and borrowing process, along with the time's, humans were introduced to a system called banking. Now banking is impressive and is considered as a forum for practicing usury. In this case, Islamic law as a law with different characteristics or characteristics from other laws is expected to
\end{abstract}

email koresproden: doliwitro01@gmail.com

https://creativecommons.org/licenses/by-nc/4.0/

Copyright (c) 2019 by al-huquq. All Right Reserved 
Nilai Wasathiyah dan Harakah dalam Hukum Ekonomi Syariah: Sebuah Pendekatan Filosofis Sikap dan Persepsi Bankir terhadap Bunga Bank

provide solutions to these problems. The characteristics of Islamic law are takamul (perfect), wasathiyah (balanced), and harakah (moving). This article uses a qualitative approach that is the library in nature. Apart from that, this article also uses a philosophical approach. The materials used in this research come from books and journals. The data in this article are presented in a narrative-descriptive manner. The analysis technique used is data reduction, data presentation, and concluding. The results of the analysis show that in the philosophy of Islamic economic law, the value of wasathiyah is defined as balance (middle), and harakah is defined as a movement. In answering contemporary economic problems, it is necessary to look at the wasathiyah (balance) point of view between the two parties which carry out the transaction process. By using a philosophical approach guided by the values of wasathiyah and harakah, there are three perceptions and views of bankers on bank interest, namely pragmatic bankers, realistmodernist bankers, and fundamentalist bankers)

\section{Kata Kunci:}

Wasathiyah, Harakah, Bankir, Bunga Bank, Riba.

\section{Pendahuluan}

Dalam mengatur kehidupan manusia, Allah menurunkan syariat (hukum) Islam sebagai pedoman, baik untuk manusia sebagai anggota masyarakat maupun dirinya pribadi ${ }^{1}$. Hal ini berbeda dengan hukum lain yang hanya mengatur kehidupan manusia dalam status sebagai anggota masyarakat saja. Cicero mengatakan ubi societas ibi ius yang bermakna di mana ada masyarakat di sana ada hukum. Meskipun hukum Islam merupakan hak prerogatif Allah yang menentukan segala-galanya, namun manusia di sini sebagai subjek hukum dapat melakukan ijtihad untuk menentukan hukum

1 Nurrohman Nurrohman and Nurhaeti Nurhaeti, "Pemikiran Ekonomi Mikro Islam Dalam Lintasan Sejarah," Jurnal Ilmu Akuntansi Dan Bisnis Syariah, Vol. 1, No. 1 (2019): 277, https://journal.uinsgd.ac.id/index.php/aksy/article/view/5558. 
tersebut sesuai dengan kondisi dan situasi tertentu selama tidak keluar dari Al-Qur'an dan Hadis².

Hukum Islam mengatur semua aspek kehidupan manusia, termasuk muamalah ${ }^{3}$. Kegiatan muamalah yang dilakukan manusia tidak terlepas dari proses pinjam meminjam antar satu sama lain. Dalam proses pinjam meminjam ini, seiring perkembangan zaman manusia dikenalkan dengan sebuah sistem yang bernama perbankan. Bank merupakan badan yang bergerak di bidang jasa keuangan dan intermediasi, maka tidak heran jika ada imbalan (profit) atas jasa yang disediakan oleh pihak bank. Dengan adanya imbalan dapat membantu bank untuk menjamin dan menjaga eksistensinya di tengah-tengah nasabah. Imbalan tersebut dalam bahasa lain disebut juga dengan istilah "bunga". Sebagian masyarakat ada yang menganggap bahwa bunga terkesan mengeksploitasi nasabah dalam sistem kredit. Berangkat dari hal ini kemudian pinjaman kredit pada bank selalu disertai dengan jumlah bunga yang telah ditetapkan, baik bunga dalam jatuh tempo, maupun bunga yang berasal dari modal pinjaman itu sendiri ${ }^{4}$.

Berdasarkan uraian di atas, kini bank terkesan dan dianggap sebagai wadah yang menjalankan praktek riba. Al-Asymawy mengemukakan bahwa riba itu identik dengan sesuatu yang

2 Ahmad Mukri Aji, "Dinamisasi Hukum Islam Di Indonesia," Mizan; Jurnal Ilmu Syariah, Vol. 4, No. 2 (2016): 254, https://doi.org/https://doi.org/10.32507/mizan.v4i2.182.

3 Iqbal Imari, "Rekonstruksi Akad Perbankan Syariah Berdasar Maqashid Syariah," Islamic Economics Journal, Vol. 2, No. 2 (2016): 236, https://doi.org/10.21111/iej.v2i2.1392; Doli Witro, "Praktek Jual Beli Parang Dengan Cara Penumpukan Untuk Meningkatkan Harga Di Desa Koto Padang Perspektif Hukum Islam," Al-Qisthu: Jurnal Kajian Ilmu-Ilmu Hukum, Vol. 17, No. 1 (2019): 35, https://doi.org/10.32694/010710.

${ }^{4}$ Harun Harun, "Riba Menurut Pemikiran M. Quraish Shihab (Tela'ah Illat Hukum Larangan Riba Dalam Al-Qur'an)," Suhuf, Vol. 27, No. 1 (2015): 40, http://journals.ums.ac.id/index.php/suhuf/article/view/668; Abdul Ghofur, "Konsep Riba Dalam Al-Qur'an," Economica: Jurnal Ekonomi Islam, Vol. 7, No. 1 (2016): 19, https://doi.org/10.21580/economica.2016.7.1.1030; Nurhadi Nurhadi, "Tematik Hadis Tentang Riba Dalam Kitab Shahih Bukhari," Syarikat: Jurnal Rumpun Ekonomi Syariah, Vol. 2, No. 1 (2019): 78, https://doi.org/10.25299/syarikat.2019.vol2(1).3726. 
Nilai Wasathiyah dan Harakah dalam Hukum Ekonomi Syariah: Sebuah Pendekatan Filosofis Sikap dan Persepsi Bankir terhadap Bunga Bank

bertambah, baik yang berasal dari sesuatu yang diharamkan atau dihalalkan ${ }^{5}$. Dalam hal ini, hukum Islam sebagai hukum yang mempunyai karakteristik atau watak yang berbeda dengan hukum lainnya diharapkan dapat memberikan solusi atas permasalahan tersebut. Adapun karakteristik yang dimiliki hukum Islam yaitu takamul (sempurna), wasathiyah (seimbang) dan harakah (bergerak)6. Dalam menetapkan hukum riba selalu terjadi perdebatan dan menjadi salah satu permasalahan yang banyak didiskusikan kalangan muslim. Hal ini disebabkan oleh persepsi masyarakat dan konsekuensi bahwa bunga bank termasuk riba.

Penelitian mengenai bunga bank dan riba telah dilakukan, beberapa di antaranya: Ummi Kalsum, "Riba dan Bunga Bank dalam Islam (Analisis Hukum dan Dampaknya terhadap Perekonomian Umat)"7; Marwini, "Kontroversi Riba dalam Perbankan Konvensional dan Dampaknya terhadap Perekonomian"8; Abdul Mujib" "Realitas Sistem Perbankan Syariah dan Ekonomi Islam"9; Sehani, "Analisis Persepsi dan preferensi Masyarakat Pesantren terhadap Bank Syariah (Studi pada Masyarakat Pesantren di Kota Pekan Baru)"10; Moh. Indra

5 Ahmad Dakhoir and Jefry Tarantang, HUKUM BUNGA BANK (Pendekatan Fikih Wasathiyah Iqtishadiyah), ed. Ibnu Elmi A. S. Pelu (Yogyakarta: Penerbit K-Media, 2020), 1.

6 Sya'ban Mauluddin, "Karakteristik Hukum Islam (Konsep Dan Implementasinya)," Jurnal Ilmiah Al-Syir'ah, Vol. 2, No. 1 (2016): 1, https://doi.org/10.30984/as.v2i1.218; Erlan Naofal, “Urgensi Ijtihad Dalam Pengembangan Hukum Islam Di Indonesia," n.d., 2, https://www.ptamedan.go.id/index.php/2016-12-22-04-37-57/artikel-anda/850-urgensiijtihad-dalam-pengembangan-hukum-islam-di-indonesia.

7 Ummi Kalsum, "RIBA DAN BUNGA BANK DALAM ISLAM (Analisis Hukum Dan Dampaknya Terhadap Perekonomian Umat)," Jurnal Al-'Adl, Vol. 7, No. 2 (2014): 67-83, https://doi.org/10.31332/aladl.v7i2.220.

8 Marwini, "Kontroversi Riba Dalam Perbankan Konvensional Dan Dampaknya Terhadap Perekonomian," Az Zarqa', Vol. 9, No. 1 (2017): 1-18.

9 Abdul Mujib, "Realitas Sistem Perbankan Syariah Dan Ekonomi Islam," Jurnal Masharif Al-Syariah: Jurnal Ekonomi Dan Perbankan Syariah, Vol. 2, No. 1 (2017): 1-17, https:// doi.org/10.30651/jms.v2i1.761.

10 Sehani Sehani, "ANALISIS PERSEPSI DAN PREFERENSI MASYARAKAT PESANTREN TERHADAP BANK SYARIAH (Studi Pada Masyarakat Pesantren Di Kota Pekanbaru)," JURNAL AL-IQTISHAD, Vol. 13, No. 1 (2017): 1-18, https://doi.org/10.24014/jiq.v13i1.4385. 
Bangsawan. “Eksistensi Ekonomi Islam (Studi tentang Perkembangan Perbankan Syariah di Indonesia)" 11. Perdebatan mengenai riba selalu terjadi: pertama, sebagian Muslim percaya bahwa penjelasan mengenai bunga adalah riba sebagaimana yang terdapat dalam fiqih (hukum Islam) merupakan penjelasan yang tepat dan harus diikuti oleh umat Islam; dan kedua, pandangan yang mengemukakan bahwa penjelasan bunga bank adalah riba dalam literatur fikih belum mempertimbangkan tujuan moral dan belum memadai dari pengharaman riba sebagaimana yang dijelaskan oleh Al-Qur'an dan Hadis ${ }^{12}$.

Berangkat dari penjelasan di atas penulis ingin melihat pandangan bankir tentang bunga bank merupakan riba atau tidak dengan pendekatan filosofis menggunakan teori karakteristik hukum Islam yaitu wasathiyah dan harakah. Dengan adanya dua karakteristik ini maka diharapkan mampu menjelaskan keseimbangan dan bergeraknya hukum berdasarkan situasi dan kondisi saat ini. Tulisan ini bertujuan menyoroti persepsi bankir mengenai bunga bank yang beredar di masyarakat saat ini dengan menggunakan pendekatan filosofis yang dibantu dengan karakteristik hukum Islam yaitu wasathiyah dan harakah. Perlu ditegaskan disini tulisan ini tidak mengkaji hukum bunga bank dalam bab fiqih sehingga menghasilkan kesimpulan dibolehkan atau dilarangnya bunga bank, namun lebih kepada persepsi seseorang yang berpandangan halal, haram atau antara halal dan haram terhadap praktek bunga bank.

\section{Metode Penelitian}

Artikel ini menggunakan pendekatan kualitatif yang bersifat pustaka. Selain itu, artikel ini juga menggunakan pendekatan filosofis. Bahan-bahan yang digunakan dalam penelitian ini berasal dari bukubuku dan jurnal-jurnal. Bahan primer dalam penelitian ini diambil dari penelitian Dakhoir dan Tarantang yang dituangkan dalam buku yang berjudul Hukum Bunga Bank (Pendekatan Fikih Wasathiyah

${ }^{11}$ Moh. Indra Bangsawan, “Eksistensi Ekonomi Islam (Studi Tentang Perkembangan Perbankan Syariah Di Indonesia)," Law and Justice, Vol. 2, No. 1 (2017): 24-34, https:/ / doi.org/10.23917/laj.v2i1.4334.

12 Dakhoir and Tarantang, HUKUM BUNGA BANK (Pendekatan Fikih Wasathiyah Iqtishadiyah), 3-4. 
Nilai Wasathiyah dan Harakah dalam Hukum Ekonomi Syariah: Sebuah Pendekatan Filosofis Sikap dan Persepsi Bankir terhadap Bunga Bank

Iqtishadiyah). Selain bahan primer tersebut didukung oleh bahan sekunder yaitu jurnal-jurnal yang berkaitan dengan nilai wasathiyah, harakah, riba dan bunga bank. Data dalam artikel ini diperoleh dengan cara membaca, menelaah dan memahami sebanyak-banyak bahan yang telah dikumpulkan. Data dalam artikel ini disajiakan dengan naratif-deskriptif. Teknik analisis yang digunkan adalah reduksi data, penyajian data, dan penarikan kesimpulan ${ }^{13}$.

\section{Wasathiyah dalam Hukum Islam}

Wasathiyah berasal dari kata wustha dalam bahasa arab yang artinya tengah, atau "wasathan" yang berarti pertengahan di antara dua batas, keadilan, sedang-sedang saja, atau standar ${ }^{14}$. Kata wasath muncul sebanyak tiga kali dalam Al-Qur'an pada surah al-Baqarah ayat 143 , ayat 238 , dan surah al-Qalam ayat $48^{15}$. Al-Asfahaniy dalam Mufradat al-Fadzul Qur'an mengartikan wasathan sama dengan sawa'un tengah-tengah dua batas. Wasathan bisa juga diartikan dengan tafrith dan ifrath di dalam kehidupan beragama. Ibnu 'Asyur membagi arti kata wasath dengan dua makna, yaitu: 1) kata wasath secara etimologi diartikan sesuatu yang ukuran sebanding jika dilihat dari dua belah ujung atau sesuatu yang berada di tengah; dan 2) kata wasath secara terminologi merupakan nilai-nilai Islam yang berdasarkan mindset pertengahan dan lurus, dan tidak condong (berat sebelah) terhadap sesuatu tertentu. Al-Thabari juga memberikan pengertian senada

13 Matthew B. Miles and A. Michael Huberman, Qualitative Data Analysis (a Source Book of New Methods) (Beverly Hills: Sage Publications, 1984), 21-24.

14 Subhan Hi Ali Dodego and Doli Witro, "Islamic Moderation as a Solution to Prevent Radicalism and Extremism Religious in Indonesia," Dialog, Vol. 43, No. 2 (2020): 201, https://doi.org/10.47655/dialog.v43i2.375; Betria Zarpina Yanti and Doli Witro, "Islamic Moderation as a Resolution of Different Conflicts of Religion," Andragogi: Jurnal Diklat Teknis Pendidikan Dan $\begin{array}{llllll}\text { Keagamaan, } & \text { Vol. } & \text { 8, No. } & 1 & \text { (2020): }\end{array}$ https://doi.org/https://doi.org/10.36052/andragogi.v8i1.127.

${ }^{15}$ Dakhoir and Tarantang, HUKUM BUNGA BANK (Pendekatan Fikih Wasathiyah Iqtishadiyah), 68. 
dalam mengartikan kata wasath berarti adil, komprehensif, dan terpilih dikarenakan terintegrasi semua aspek kehidupan manusia ${ }^{16}$.

Mengutip dari Azyumardi Azra, dalam Dakhoir dan Tarantang menyatakan bahwa dalam terminologi kajian keislaman, konsep wasathiyah di dunia internasional Islam diinterpretasikan sebagai justly-balanced Islam atau Islam yang seimbang dan berkeadilan, juga middle path Islam atau Islam pertengahan17. M. Quraish Shihab mengartikan wasath sebagai sebuah keseimbangan yang baik dan sesuai dengan objeknya dan kebaikan dinilai baik jika berada pada pertengahan, tidak terlalu condong ke kanan dan tidak pula ke kiri. Nilai wasath ini tampak pada wasit dalam suatu pertandingan yang menjadi penengah dan saksi yang adil, tidak memihak salah satu dan tidak pula memenangkan salah satu pihak dengan nafsu ${ }^{18}$.

Dakhoir dan Tarantang mendefinisikan wasathiyah dengan melihat keteraturan tatanan alam semesta yang bergerak seimbang dan sesuai degan orbitnya, sehingga wasathiyah diartikan sebagai sebuah paradigma yang tercermin dalam tingkah laku ideal dan proporsional19. Kholid juga mendefinisikan wasathiyah ke dalam prinsip keseimbangan yang adil dalam menanggapi kepentingan individu dan masyarakat termasuk kepemilikan alat produksi dan

16 Trini Diyani, "Implementasi Paradigma Islam Wasathiyah; Strategi Menjaga Masa Depan Keindonesiaan," SALAM: Jurnal Sosial Dan Budaya Syar'i, Vol. 6, No. 3 (2019): 313, https://doi.org/10.15408/sjsbs.v6i3.13193.

17 Irham Yuwanamu, "Bentuk Islam Faktual: Karakter Dan Tipologi Islam Indonesia," El-Harakah, Vol. 18, No. 2 (2016): 204, https://doi.org/10.18860/el.v18i2.3684; Dakhoir and Tarantang, HUKUM BUNGA BANK (Pendekatan Fikih Wasathiyah Iqtishadiyah), 68.

18 Abdur Rauf, "Ummatan Wasațan Menurut M. Quraish Shihab Dalam Tafsir Al-Misbah Dan Relevansinya Dengan Nilai-Nilai Pancasila," Jurnal Studi Ilmu-Ilmu Al-Qur'an Dan Hadis, Vol. 20, No. 2 (2019): 261, https://doi.org/10.14421/qh.2019.2002-06; Zainun Wafiqatun Niam, "Konsep Islam Wasathiyah Sebagai Wujud Islam Rahmatan Lil 'alamin: Peran $\mathrm{Nu}$ Dan Muhammadiyah Dalam Mewujudkan Islam Damai Di Indonesia," Palita: Journal of Social Religion Research, Vol. 4, No. 2 (2019): 9495, https://doi.org/10.24256/pal.v4i2.764.

${ }_{19}$ Dakhoir and Tarantang, HUKUM BUNGA BANK (Pendekatan Fikih Wasathiyah Iqtishadiyah), 14. 
faktor produksi ${ }^{20}$. Dalam konteks hukum Islam, konsep wasathiyah dimaknai juga dengan sikap moderat, dan menjadi salah satu dari tiga karakter hukum Islam yang memperhatikan keseimbangan fakta ideal dan harapan ${ }^{21}$. Kemudian Hilmi menambahkan bahwa konsep wasathiyah menaruh perhatian pada keadaan sosial yang sejalan dengan nilai-nilai keislaman 22 .

Menanggapi hal tersebut, Dakhoir dan Tarantang mengungkapkan ketidaksepakatan terhadap makna wasathiyah yang disejajarkan dengan konsep moderat, karena menurut mereka moderat adalah sikap tengah-tengah yang menghindar dari problematika ekstremis yang berkompromi dengan win-win solution, sementara wasathiyah terikat akan syari'at yang lebih komprehensif dan esensial23. Wasathiyah ini menjadi sebuah konsep dengan sudut pandang dan bertingkah laku yang seimbang dan tidak berlebihan (ifrath) dalam beragama dan tidak pula mengurangi ajaran agama (tafrith) ${ }^{24}$. Makna wasathiyah tidak dimaknai dari pemahaman ekstremis yang bertendensi pada kekerasan, dan ini tentu menjadi pemahaman yang berlebihan dari yang seharusnya. Di sisi lain, ada pula pemahaman kaum liberalis yang cenderung menggampangkan nilai agama hingga melampaui ketentuan dasar dan tindakan seperti ini dapat mengurangi esensi ajaran itu sendiri.

Wasathiyah dalam dunia Islam menjadi sebuah konsep pertengahan yang menawarkan kedamaian dengan sikap yang seimbang dan berkeadilan. Wasathiyah tidak berorientasi ke kanan yang menitikberatkan pada kebatinan, dan tidak pula ke kiri yang mengagungkan materi. Tidak menjadi konsep yang terang-terangan melebihkan dan mengurangkan ajaran, juga tidak berada pada garis abu-abu menghindari perdebatan, melainkan berupaya menemukan jalan tengah dengan sudut pandang yang adil dan seimbang serta

${ }^{20}$ Muhamad Kholid, "Prinsip-Prinsip Hukum Ekonomi Syariah Dalam Undang-Undang Perbankan Syariah," Asy-Syari'ah, Vol. 20, No. 2 (2018): 149, https://doi.org/10.15575/as.v20i2.3448.

${ }^{21}$ Aji, “Dinamisasi Hukum Islam Di Indonesia,” 267.

22 Danial Hilmi, Mengurai Islam Moderat Sebagai Agen Rahmatan Lil 'Alamin (Malang: UIN Maliki Press, 2016), 66.

${ }^{23}$ Dakhoir and Tarantang, HUKUM BUNGA BANK (Pendekatan Fikih Wasathiyah Iqtishadiyah), 16.

${ }^{24}$ Dakhoir and Tarantang, 72. 
menjadi saksi dan disaksikan kesaksiannya. Ada beberapa nilai penting dalam konsep wasathiyah, antara lain:

Pertama, memahami dan mampu menghayati potensi yang dimiliki manusia baik potensi ruhani, fisik, dan jiwa yang berlandaskan keseimbangan; Kedua, menghargai kehidupan orang lain dan kehidupan sosial bermasyarakat serta menyadari bahwa manusia merupakan makhluk yang membutuhkan satu sama lain; Ketiga, menerima setiap keragaman dalam berbagai hal yang terdapat di tengah masyarakat baik dari segi suku bangsa, warna kulit, keragaman fisik, pemikiran, pandangan, keyakinan, dan sebagainya; Keempat, mampu berkomunikasi dan berinteraksi sosial serta berdialog secara terbuka dengan semua golongan yang ada di masyarakat, meskipun memiliki budaya, peradaban, dan agama yang berbeda; Kelima, mampu memberikan keseimbangan terhadap kehidupan dunia yang bersifat materialisme dengan kehidupan akhirat (spiritualisme), begitu juga dengan tidak hanya kebutuhan rohani semata, tetapi juga memperhatikan kebutuhan jasmani; Keenam, memiliki sifat yang pertengahan, tidak ekstrem, adil, dapat membuat pilihan dengan bijak dan tidak merasa benar sendiri; Ketujuh, mampu memberikan contoh perilaku tasamuh (toleransi) yang tercermin dalam sikap terbuka, menerima perbedaan, salin menghargai dan menghormati eksistensi pihak yang berbeda paham; dan Kedelapan, menjadi teladan bagi yang lain dan menjadi saksi atas terimplementasikannya konsep keseimbangan ${ }^{25}$.

\section{Harakah dalam Hukum Islam}

Harakah merupakan salah satu karakteristik syari'ah setelah ta'amul (sempurna) dan wasathiyah (seimbang) ${ }^{26}$. Harakah mampu menunjukkan kemampuan akomodasi hukum secara dinamis dan tanggap dalam merespon setiap problematika baru yang tidak ada

${ }^{25}$ Kamrani Buseri, "Islam Wasathiyah Dalam Perspektif Pendidikan," 2015, 4-5, https://idr.uin-antasari.ac.id/6773/1/ISLAM WASATHIYAH DALAM PERSPEKTIF PENDIDIKAN.pdf.

${ }^{26}$ Bahrul Ulum Annafi, "FORMALISASI SYARI'AH (Penormaan Dan Karakteristik Prinsip Syari'ah Dalam Hukum Nasional Indonesia)," Jurnal Hukum, 2014,

11, http://hukum.studentjournal.ub.ac.id/index.php/hukum/article/view/714 
hukumnya. Eksistensi harakah adalah sebagai sebuah konsekuensi logis atas pergerakan hidup masyarakat yang tidak pernah berhenti akibat pesatnya kemajuan sosial yang tidak bisa dihindari. Hukum Islam yang telah terjilid sejak ribuan tahun lalu, sengaja Allah sifati universal agar mampu ditafsirkan dan menjawab setiap problematika dan bermakna untuk setiap lini kehidupan sehingga dapat digunakan pada setiap tempat dan waktu.

Mukri mendefinisikan harakah sebagai hukum Islam yang dinamis dan terus berkembang seiring dengan perkembangan zaman $^{27}$. Dakhoir dan Tarantang pun mengartikan hal yang senada bahwa harakah adalah konsep yang dinamis dan mampu bergerak secara fleksibel dan berkelanjutan. Adanya prinsip harakah, membuat hukum Islam tampak selalu hidup dan relevan dengan setiap permasalahan. Sehingga dalam konteks pengembangan konsep fikih wasathiyah iqtishadiyah dan maliyah, harakah yang dinamis perlu memperhatikan lima prinsip untuk menjaga objektivitas dan kemurnian hukum itu sendiri yakni tawasuth (jalan tengah), tawazun (seimbang), syura (musyawarah), aulawiyah (prioritas), tahadhdhur (berkeadaban) ${ }^{28}$.

Harakah (dinamis) sebagai satu di antara karakteristik hukum Islam dapat menjadi sesuatu yang dapat merespon, mengakomodir, dan menjawab permasalahan baru yang belum ada hukumnya dalam nash (Al-Qur'an dan hadis). Sehingga dampak hal tersebut yang tidak dapat dihindari adalah kemajuan dan perubahan sosial. Tidak terlepas dalam bidang muamalah, hukum Islam sebagai hukum yang elastis dan dinamis dapat mengakomodir perubahan dan kondisi sosial yang ada. Pranata ijtihad disiapkan oleh hukum Islam untuk instrumen rechtsvinding (penemuan hukum) dalam hukum Islam itu sendiri. Oleh karenanya, dengan adanya instrumen ini, hukum Islam tidak akan mengalami dengan apa yang diistilah rechtvacuum (kekosongan hukum) ${ }^{29}$.

\footnotetext{
27 Aji, “Dinamisasi Hukum Islam Di Indonesia,” 266.

28 Dakhoir and Tarantang, HUKUM BUNGA BANK (Pendekatan Fikih Wasathiyah Iqtishadiyah), 39.

${ }_{29}$ Naofal, "Urgensi Ijtihad Dalam Pengembangan Hukum Islam Di Indonesia," 2.
} 


\section{Nilai Wasathiyah dan Harakah Hukum Ekonomi Syariah: Persepsi dan Sikap Bankir terhadap Hukum Bunga Bank}

Para bankir memiliki pandangan beragam tentang bunga bank. Hal ini disebabkan oleh para bankir memiliki pengetahuan yang berbeda dalam memandang bunga bank. Dari hasil penelitian Dakhoir dan Tarantang mengemukakan setidaknya ada tiga pandangan bankir dalam memandang bunga bank yaitu: 1) Bankir pragmatis; 2) Bankir realis-modernis (moderat); dan 3) bankir fundamentalis. Ketiga kategori bankir tersebut memiliki pandangan yang berbeda dalam memahami bunga bank ${ }^{30}$.

Pertama, bankir pragmatis. Corak pemikiran pragmatis bila dilihat dalam dunia filsafat dikenalkan oleh William James ${ }^{31}$, John Dewey $^{32}$, dan Charles Sanders Peirce ${ }^{33}$. Tokoh-tokoh inilah yang mengembangkan paham pragmatisme dalam dunia filsafat. Mereka memberikan pengertian bahwa pragmatisme adalah aliran yang membuktikan dirinya sebagai sesuatu yang benar dan aliran yang mengajarkan mengenai kebenaran yang akibat-akibat perantaraannya dapat bermanfaat.

Bila dilihat dari makna kata, pragmatism berasal dari bahasa Yunani yaitu pragma berarti kejadian, benda, fakta, sesuatu yang dibuat. Menurut Kamus Besar Bahasa Indonesia, pragmatis adalah mengutamakan manfaat yang bersifat berguna untuk umum yang bersifat praktis. Dilihat dari aspek teknikal, pragmatisme ialah teori yang menjelaskan kebenaran dan maksud melalui kepercayaan atau aplikasi ide kepada tindakan yang memiliki kesan praktikal. Pragmatisme berusaha untuk mempertemukan filsafat dan ilmu

30 Dakhoir and Tarantang, HUKUM BUNGA BANK (Pendekatan Fikih Wasathiyah Iqtishadiyah), 37-38.

31 Heidi White, "William James's Pragmatism," European Journal of Pragmatism and American Philosophy, Vol. 2, No. 1 (2010), https://doi.org/10.4000/ejpap.941.

32 Dimitris Pavlis and John Gkiosos, "John Dewey, From Philosophy of Pragmatism to Progressive Education," Journal of Arts and Humanities, Vol. 6, No. 9 (2017): 23-30, https:/ / doi.org/10.18533/journal.v6i9.1257.

33 Nathan Houser, "Peirce's Post-Jamesian Pragmatism," European Journal of Pragmatism and American Philosophy, Vol. 3, No. 1 (2011), https://doi.org/10.4000/ejpap.866. 
Nilai Wasathiyah dan Harakah dalam Hukum Ekonomi Syariah: Sebuah Pendekatan Filosofis Sikap dan Persepsi Bankir terhadap Bunga Bank

pengetahuan agar filsafat berguna bagi kehidupan manusia yang bisa dipraktekkan dalam masyarakat dan bersifat ilmiah ${ }^{34}$.

Bankir pragmatis menganggap bahwa tambahan yang didapat seorang dari proses pinjam meminjam dan jual beli yang disebut dengan bunga, merupakan keuntungan yang dapat diambil dari suatu proses bisnis perbankan. Perbankan merupakan lembaga yang berbadan hukum perusahan, tentu net profit merupakan tujuan akhir dari keuangan dan bisnis yang dijalankan. Tipe dan sikap bankir pragmatis disini memahami bunga bukan merupakan praktik riba. Bankir pragmatis tidak memiliki kegelisahan apalagi alasan untuk berhenti bekerja dalam lembaga perbankan, baik bank konvensional maupun bank syariah. Lebih lanjut, bankir ini mengemukakan bahwa bunga dan riba merupakan dua sesuatu yang terpisah, dan dua bagian dari sebuah proses yang terus mencari bentuk ${ }^{35}$.

Untuk mengetahui ciri-ciri bankir pragmatisme bisa dilihat dengan tiga cara, antara lain melalui: 1) dari sisi fiqrah (ide dan pemikiran), bankir pragmatis tidak memperhatikan hal-hal yang bersifat normatif; 2) dari sisi harakah (gerakan), bankir anti absolutisme. Bankir pragmatis tidak memandang bahwa bunga atau riba merupakan sebuah transaksi bebas dan berdasarkan kebenaran relatif. Namun dalam hal ini bankir pragmatis mengemukakan bahwa praktek bunga bank, tidak ada pihak yang dirugikan karena sebelum melakukan proses transaksi pinjam meminjam kedua belah pihak telah bersepakat; 3) dari sisi amaliyah (perbuatan nyata), atau dalam pada tataran implementasinya yang dilihat dari cara berpikir, gerakan (tindakan), dan sikap bankir pragmatis tidak "mendua" (anti dualisme), mereka tidak goyah dan teguh berpendirian pada prinsip bahwa operasional perbankan baik syariah maupun bank konvensional berorientasi kepada bisnis yang mendatang kemaslahatan untuk pertumbuhan ekonomi umat ${ }^{36}$.

Kedua, bankir realistis-modernis. Realisme merupakan pola atau sikap yang mengikuti arus. Seseorang yang memiliki pandangan realistis akan mengabaikan semua/ beberapa nilai atau prinsip yang

${ }^{34}$ Dakhoir and Tarantang, HUKUM BUNGA BANK (Pendekatan Fikih Wasathiyah Iqtishadiyah), 38.

${ }^{35}$ Dakhoir and Tarantang, 38-39.

36 Dakhoir and Tarantang, 39-40. 
diyakini dan akan cenderung mengikuti lingkungan di mana ia berada. Realisme ini tumbuh dalam pikiran dan jiwa seseorang secara perlahan. Realisme tidak hanya terdapat level individu saja, bahkan sampai kepada tingkat negara. Individu yang dipengaruhi oleh nilainilai realisme, berkaitan dengan hal-hal yang bersifat materi. Tetapi tidak menutup kemungkinan terjadi juga pada hal-hal lain seperti sistem kepercayaan, budaya politik, dan hal lainnya. Dalam pandangan realis-modernis mengambil keuntungan berlebih atau dalam bahasa lain mengambil laba melalui bunga bank konvensional atau keuntungan bank syariah misalnya dari hasil sewa menyewa, jual beli dan jasa serta pinjam meminjam, keduanya sama-sama merupakan hal yang tidak dibolehkan. Oleh karenanya, menurut bankir realis-modernis, berkerja di bank syariah maupun bank konvensional sama saja ${ }^{37}$.

Bankir realis-mordernis mengemukan bahwa akad dalam transaksi keuangan bank syariah maupun keuanga bank konvensional merupakan sesuatu yang belum final. Maka bankir realis-mordernis memilki pemikiran untuk berhenti dari bank syariah atau bank konvensional ketika terdapat perilaku yang zalim. Hal tersebut merupakan kegelisahan bagi para bankir realis-modernis. Pandangan ini lahir karena bankir realis-modernis memiliki persepsi bahwa perbuatan mengambil keuntungan secara sepihaklah yang menjadi ukuran haram atau tidak sebuah pekerjaan. Bankir realismodernis memilih nilai-nilai dan prinsip-prinsip substantif tentang bunga bank atau keuntungan dalam bank syariah. Namun di sisi lain bankir realis-modernis menyadari segala sesuatu membutuhkan proses sehingga mereka bisa berpikir realistis ${ }^{38}$.

Cara berpikir dan sikap seperti inilah dalam agama Islam disebut dengan wasathiyah. Dengan adanya wasathiyah seseorang akan dapat melahirkan sikap tasamuh dan toleransi kepada yang lain, tidak gegabah dan lebih dewasa memandang sesuatu ${ }^{39}$. Begitu juga dengan bankir yang toleran terhadap mengambil dalam keuntungan jual beli

${ }^{37}$ Dakhoir and Tarantang, 39-40.

38 Dakhoir and Tarantang, 40.

${ }^{39}$ Betria Zarpina Yanti and Doli Witro, "Self Maturity and Tasamuh as a Resolution of Religious Conflicts," Intizar, Vol. 25, No. 2 (2019): 89, https://doi.org/https://doi.org/10.19109/intizar.v25i2.5608. 
dan bunga bank dari sisi kemaslahatan umat yang terukur dan terlihat jelas yang tidak menzalimi siapapun ${ }^{40}$.

Ketiga, bankir fundamentalis, bankir ini disebut juga dengan bankir idealis. Bankir idealis memandang hukum bunga lebih fundamental yaitu sesuatu yang ditetapkan Al-Qur'an dan hadis merupakan sesuatu yang bersifat mutlak. Istilah idealisme pertama kali diperkenalkan oleh Leibniz ${ }^{41}$, pada awal abad 18 di dalam dunia filsafat. Istilah ini digunakan untuk menjadi lawan dari istilah materialisme epikuros. Selain itu, Leibniz juga menerapkan istilah ini dalam pemikiran plato. Idealisme berasal dari kata ide yang berarti dunia dalam jiwa. Oleh karena itu, pandangan ini merendahkan halhal yang bersifat materi dan fisik serta mengutamakan hal-hal yang bersifat ide. Dalam menjelaskan realitas, penganut idealisme tidak menjelaskan dengan materi tetapi menjelaskan dengan melihat gejalagejala psikis, budi, roh, pikiran mutlak, dan diri seseorang42.

Ada beragam pengertian yang dikemukan oleh para ahli mengenai idealisme. Fichte ${ }^{43}$, menggunakan istilah idealisme subjektif yaitu subjek-subjek tertentu yang diperoleh dari pandanganpandangan etika manusia yang ideal yang disandarkan pada keunggulan moral. Ahli lain, Hegel ${ }^{44}$, mengemukan ada dua macam idealisme yaitu idealisme subjektif dan idealisme objektif untuk mendeskripsikan secara berturut-turut baik tesis dan antitesis. Hegel memiliki pandangan tersendiri dalam hal ini dengan apa yang disebut idealisme absolut. Idealisme absolut ini akan digunakan sebagai sintesis yang lebih tinggi dibanding unsur-unsur yang

${ }^{40}$ Dakhoir and Tarantang, HUKUM BUNGA BANK (Pendekatan Fikih Wasathiyah Iqtishadiyah), 40.

${ }^{41}$ John Whipple, "Leibniz on Fundamental Ontology: Idealism and Pedagogical Exoteric Writing," Ergo, an Open Access Journal of Philosophy, Vol 4, No. 11 (2017): 301-47, https://doi.org/10.3998/ergo.12405314.0004.011.

${ }^{42}$ Dakhoir and Tarantang, HUKUM BUNGA BANK (Pendekatan Fikih Wasathiyah Iqtishadiyah), 40-41.

${ }^{43}$ Rory Lawrence Phillips, "Transcendental Idealism and Naturalism: The Case of Fichte," Journal of Transcendental Philosophy, Vol. 1, No. 1 (2020): 43-62, https://doi.org/10.1515/jtph-2019-0013.

${ }^{44}$ Markus Gabriel, "What Kind of an Idealist (If Any) Is Hegel?," Hegel Bulletin, Vol. 37, No. 2 (2016): 181-208, https:/ / doi.org/10.1017/hgl.2016.15. 
membentuknya (idealisme) yaitu tesis dan antitesis. Kant45, mengemukakan istilah lain yaitu idealisme transendental (kritis). Dalam pandangan idealisme ini, Kant melihat ruang dan waktu merupakan formal instuisi dalam diri manusia dan pengalaman yang dialami secara langsung tidak dianggap sebagai benda dalam diri manusia. Sementar Schelling46, menggunakan istilah idealisme transendental sebagai pengganti idealisme subyektif sebagainya yang dikemukakan Hegel di atas ${ }^{47}$,

Orang yang memiliki corak pemikiran idealisme disebut dengan idealis. Sama dengan idealisme, ideal juga berakar kata "ide" yang memiliki makna bahwa sesuatu yang disebut dengan idealis merupakan suatu yang sudah tergagas atau yang mempunyai gagasan. Orang yang idealis ditandai dengan pendapat yang dikeluarkan merupakan gagasan atau pendapat yang vokal. Orang yang idealis melaksanakan setiap gagasan yang pernah ia sampaikan. Ia memperhitungkan dengan matang pendapat yang dikeluarkan dan bersiap menerima apa konsekuensi yang akan ia terima terhadap pendapat yang ia ambil. Orang yang idealis cenderung melihat segala hal sesuai dengan keyakinan yang ia miliki. Maka tidak jarang orang yang memiliki pandangan yang idealis terlihat kaku. Dalam mencapai tujuannya, ia melakukan apapun sesuai dengan pandangannya. Namun apabila tidak sesuai dengan pandangannya, maka ia menganggap hal tersebut tidak ideal ${ }^{48}$.

Seseorang yang idealis memiliki kriteria tertentu atau spesifik terhadap suatu hal. Jika standar yang mereka tetapkan terlalu tinggi, maka ia terkadang terlihat seperti seorang perfectionist. Seseorang yang idealis tampak seperti seseorang yang memahami apa yang harus dikerjakan dan lakukan. Oleh karenanya, tidak jarang ia juga terlihat seperti seseorang yang egois dengan tindakan yang begitu

45 Sami Pihlström, "Margolis on Realism and Idealism," European Journal of Pragmatism and American Philosophy, Vol. 4, No. 2 (2012), https://doi.org/10.4000/ejpap.737.

46 Pippin, "Idealism and Anti-Idealism in Modern European Thought," The Journal of Speculative Philosophy, Vol. 33, No. 3 (2019): 349-67, https://doi.org/10.5325/jspecphil.33.3.0349.

${ }^{47}$ Dakhoir and Tarantang, HUKUM BUNGA BANK (Pendekatan Fikih Wasathiyah Iqtishadiyah), 41-42.

${ }^{48}$ Dakhoir and Tarantang, 42. 
Nilai Wasathiyah dan Harakah dalam Hukum Ekonomi Syariah: Sebuah Pendekatan Filosofis Sikap dan Persepsi Bankir terhadap Bunga Bank

yakin akan kemampuannya, dan terlihat seperti orang yang bodoh, jika standar yang ditetapkan di luar kemampuannya. Dalam ranah sosial seseorang yang idealis memiliki, setidaknya ada dua ciri-ciri, yaitu konsekuen, kuat berpendirian, jujur, bertanggung jawab, dan tidak memikirkan keuntungan untuk diri sendiri. Orang yang memiliki sikap idealis memiliki keyakinan bahwa setiap langkah dan tindakannya akan diwarnai dengan kebenaran. Selain itu, orang yang idealis mementingkan cita-cita, khayalan (fantasi) untuk menggambarkan suatu keindahan meskipun yang terjadi tidak sesuai dengan kenyataan ${ }^{49}$.

Kalau dilihat dari pendekatan filosofis, bunga bank dipandang dengan fundamentalis-tekstualis oleh bankir idealis. Dengan bertindak dan bergerak (harakah), aksi dan mengeksekusi (amaliyah), dan berfikir (figrah), pandangan idealis mengemukakan akan lebih baik terlepas dari bunga bank yaitu dengan berhenti bekerja di bank konvensional dan bank syariah adalah merupakan solusi terbaik. Inilah ini yang dimaksud dalam pandangan bank fundamentalis. Hal ini disebabkan karena lalu lintas dan kinerja keuangan pada kedua bank tersebut yaitu bank syariah dan bank konvensional sama-sama mengandung atau memiliki unsur-unsur yang zalim dalam penghasilan dan praktik kerja. Berangkat dari hal tersebut bankir fundamentalis memberikan kesimpulan bahwa bunga bank secara mutlak adalah termasuk riba, menipu dan curang serta mengambil keuntungan secara berlebihan merupakan bagian dari kezaliman. Oleh karenanya, dalam dunia perbankan segala bentuk transaksi apapun hendaknya tidak dijadikan sebagai lalu lintas atau sebagai mitra keuangan ${ }^{50}$.

\section{Penutup}

Dalam filsafat hukum ekonomi syariah, nilai wasathiyah diartikan sebagai keseimbangan (pertengahan) dan harakah diartikan sebagai gerakan. Dalam menjawab permasalahan dalam ekonomi kontemporer diperlukan melihat dari sisi wasathiyah (keseimbangan) antara kedua belah pihak yang melakukan proses transaksi. Selain untuk menyesuaikan dengan kebutuhan masyarakat, diperlukan

\footnotetext{
49 Dakhoir and Tarantang, 42-43.
}

50 Dakhoir and Tarantang, 43. 
melihat dari sisi harakah (gerakan) agar dapat menyesuaikan dengan situasi dan kondisi tertentu dalam menetapkan hukum dalam suatu permasalahan. Dengan menggunakan pendekatan filosofis yang berpedoman nilai wasathiyah dan harakah, terdapat tiga persepsi dan pandangan para bankir terhadap bunga bank yaitu bankir pragmatis, bankir realis-mondernis, dan bankir fundamentalis.

\section{Daftar Pustaka}

Aji, Ahmad Mukri. "Dinamisasi Hukum Islam Di Indonesia." Mizan; Jurnal Ilmu Syariah, Vol. 4, No. 2 (2016): 253-70. https://doi.org/https://doi.org/10.32507/mizan.v4i2.182.

Annafi, Bahrul Ulum. "FORMALISASI SYARI'AH (Penormaan Dan Karakteristik Prinsip Syari'ah Dalam Hukum Nasional Indonesia)." Jurnal Hukum, 2014, 1-23. http://hukum.studentjournal.ub.ac.id/index.php/hukum/art icle/view/714.

Bangsawan, Moh. Indra. “Eksistensi Ekonomi Islam (Studi Tentang Perkembangan Perbankan Syariah Di Indonesia)." Law and Justice, Vol. 2, No. 1 (2017): 24-34. https:// doi.org/10.23917/laj.v2i1.4334.

Dakhoir, Ahmad, and Jefry Tarantang. HUKUM BUNGA BANK (Pendekatan Fikih Wasathiyah Iqtishadiyah). Edited by Ibnu Elmi A. S. Pelu. Yogyakarta: Penerbit K-Media, 2020.

Diyani, Trini. "Implementasi Paradigma Islam Wasathiyah; Strategi Menjaga Masa Depan Keindonesiaan." SALAM: Jurnal Sosial Dan Budaya Syar'I, Vol. 6, No. 3 (2019): 303-16. https://doi.org/10.15408/sjsbs.v6i3.13193.

Dodego, Subhan Hi Ali, and Doli Witro. "Islamic Moderation as a Solution to Prevent Radicalism and Extremism Religious in Indonesia." Dialog, Vol. 43, No. 2 (2020): 199-208. https://doi.org/10.47655/dialog.v43i2.375.

Gabriel, Markus. "What Kind of an Idealist (If Any) Is Hegel?" Hegel Bulletin, Vol. 37, No. 2 (2016): 181-208. https://doi.org/10.1017/hgl.2016.15.

Ghofur, Abdul. “Konsep Riba Dalam Al-Qur'an.” Economica: Jurnal Ekonomi Islam, Vol. 7, No. 1 (2016): 1-26. https:/ / doi.org/10.21580/economica.2016.7.1.1030. 
Nilai Wasathiyah dan Harakah dalam Hukum Ekonomi Syariah: Sebuah Pendekatan Filosofis Sikap dan Persepsi Bankir terhadap Bunga Bank

Harun, Harun. "Riba Menurut Pemikiran M. Quraish Shihab (Tela'ah Illat Hukum Larangan Riba Dalam Al-Qur'an)." Suhuf, Vol. 27, No. 1 (2015): 38-59. http://journals.ums.ac.id/index.php/suhuf/article/view/668

Hilmi, Danial. Mengurai Islam Moderat Sebagai Agen Rahmatan Lil 'Alamin. Malang: UIN Maliki Press, 2016.

Houser, Nathan. "Peirce's Post-Jamesian Pragmatism." European Journal of Pragmatism and American Philosophy, Vol. 3, No. 1 (2011). https:// doi.org/10.4000/ejpap.866.

Imari, Iqbal. "Rekonstruksi Akad Perbankan Syariah Berdasar Maqashid Syariah." Islamic Economics Journal, Vol. 2, No. 2 (2016): 235-46. https:/ / doi.org/10.21111/iej.v2i2.1392.

Kalsum, Ummi. "RIBA DAN BUNGA BANK DALAM ISLAM (Analisis Hukum Dan Dampaknya Terhadap Perekonomian Umat)." Jurnal Al-'Adl, Vol. 7, No. 2 (2014): 67-83. https://doi.org/10.31332/aladl.v7i2.220.

Kamrani Buseri. "Islam Wasathiyah Dalam Perspektif Pendidikan," 2015, 1-11. https://idr.uin-antasari.ac.id/6773/1/ISLAM WASATHIYAH DALAM PERSPEKTIF PENDIDIKAN.pdf.

Kholid, Muhamad. "Prinsip-Prinsip Hukum Ekonomi Syariah Dalam Undang-Undang Perbankan Syariah." Asy-Syari'ah, Vol. 20, No. 2 (2018): 145-62. https:/ / doi.org/10.15575/as.v20i2.3448.

Marwini. "Kontroversi Riba Dalam Perbankan Konvensional Dan Dampaknya Terhadap Perekonomian." Az Zarqa', Vol. 9, No. 1 (2017): 1-18.

Mauluddin, Sya'ban. "Karakteristik Hukum Islam (Konsep Dan Implementasinya)." Jurnal Ilmiah Al-Syir'ah, Vol. 2, No. 1 (2016): 1-10. https:// doi.org/10.30984/as.v2i1.218.

Miles, Matthew B., and A. Michael Huberman. Qualitative Data Analysis (a Source Book of New Methods). Beverly Hills: Sage Publications, 1984.

Mujib, Abdul. "Realitas Sistem Perbankan Syariah Dan Ekonomi Islam." Jurnal Masharif Al-Syariah: Jurnal Ekonomi Dan Perbankan Syariah, Vol. 2, No. 1 (2017): 1-17. https:// doi.org/10.30651/jms.v2i1.761.

Naofal, Erlan. "Urgensi Ijtihad Dalam Pengembangan Hukum Islam Di Indonesia," n.d., 1-9. https://www.pta- 
medan.go.id/index.php/2016-12-22-04-37-57/artikelanda/850-urgensi-ijtihad-dalam-pengembangan-hukumislam-di-indonesia.

Niam, Zainun Wafiqatun. “Konsep Islam Wasathiyah Sebagai Wujud Islam Rahmatan Lil 'alamin: Peran Nu Dan Muhammadiyah Dalam Mewujudkan Islam Damai Di Indonesia." Palita: Journal of Social Religion Research, Vol. 4, No. 2 (2019): 91-106. https:// doi.org/10.24256/ pal.v4i2.764.

Nurhadi, Nurhadi. “Tematik Hadis Tentang Riba Dalam Kitab Shahih Bukhari." Syarikat: Jurnal Rumpun Ekonomi Syariah, Vol. 2, No. 1 (2019):

75-90. https://doi.org/10.25299/syarikat.2019.vol2(1).3726.

Nurrohman, Nurrohman, and Nurhaeti Nurhaeti. "Pemikiran Ekonomi Mikro Islam Dalam Lintasan Sejarah." Jurnal Ilmu Akuntansi Dan Bisnis Syariah, Vol. 1, No. 1 (2019): 226-32. https://journal.uinsgd.ac.id/index.php/aksy/article/view/5 558.

Pavlis, Dimitris, and John Gkiosos. “John Dewey, From Philosophy of Pragmatism to Progressive Education." Journal of Arts and Humanities, Vol. 6, No. 9 (2017): 23-30. https://doi.org/10.18533/journal.v6i9.1257.

Phillips, Rory Lawrence. "Transcendental Idealism and Naturalism: The Case of Fichte." Journal of Transcendental Philosophy, Vol. 1, No. 1 (2020): 43-62. https:/ / doi.org/10.1515/jtph-2019-0013.

Pihlström, Sami. "Margolis on Realism and Idealism." European Journal of Pragmatism and American Philosophy, Vol. 4, No. 2 (2012). https://doi.org/10.4000/ejpap.737.

Pippin. "Idealism and Anti-Idealism in Modern European Thought." The Journal of Speculative Philosophy, Vol. 33, No. 3 (2019): 34967. https:// doi.org/10.5325/jspecphil.33.3.0349.

Rauf, Abdur. "Ummatan Wasațan Menurut M. Quraish Shihab Dalam Tafsir Al-Misbah Dan Relevansinya Dengan Nilai-Nilai Pancasila." Jurnal Studi Ilmu-Ilmu Al-Qur'an Dan Hadis, Vol. 20, No. 2 (2019): 223-43. https://doi.org/10.14421/qh.2019.200206.

Sehani, Sehani. "ANALISIS PERSEPSI DAN PREFERENSI MASYARAKAT PESANTREN TERHADAP BANK SYARIAH (Studi Pada Masyarakat Pesantren Di Kota Pekanbaru)." 
Nilai Wasathiyah dan Harakah dalam Hukum Ekonomi Syariah: Sebuah Pendekatan Filosofis Sikap dan Persepsi Bankir terhadap Bunga Bank

JURNAL AL-IQTISHAD, Vol. 13, No. 1 (2017): 1-18. https://doi.org/10.24014/jiq.v13i1.4385.

Whipple, John. "Leibniz on Fundamental Ontology: Idealism and Pedagogical Exoteric Writing." Ergo, an Open Access Journal of Philosophy, Vol 4, No. 11 (2017): 301-47. https://doi.org/10.3998/ergo.12405314.0004.011.

White, Heidi. "William James's Pragmatism." European Journal of Pragmatism and American Philosophy, Vol. 2, No. 1 (2010). https://doi.org/10.4000/ejpap.941.

Witro, Doli. "Praktek Jual Beli Parang Dengan Cara Penumpukan Untuk Meningkatkan Harga Di Desa Koto Padang Perspektif Hukum Islam." Al-Qisthu: Jurnal Kajian Ilmu-Ilmu Hukum, Vol. 17, No. 1 (2019): 34-40. https:/ / doi.org/10.32694/010710.

Yanti, Betria Zarpina, and Doli Witro. "Islamic Moderation as a Resolution of Different Conflicts of Religion." Andragogi: Jurnal Diklat Teknis Pendidikan Dan Keagamaan, Vol. 8, No. 1 (2020): 446-57.

https://doi.org/https://doi.org/10.36052/andragogi.v8i1.127

- - - "Self Maturity and Tasamuh as a Resolution of Religious Conflicts." Intizar, Vol. 25, No. 2 (2019): 87-94. https://doi.org/https://doi.org/10.19109/intizar.v25i2.5608.

Yuwanamu, Irham. "Bentuk Islam Faktual: Karakter Dan Tipologi Islam Indonesia." El-Harakah, Vol. 18, No. 2 (2016): 199-221. https://doi.org/10.18860/el.v18i2.3684. 